\title{
Prevalence and the Risk Factors of Haemorrhoids among the Patients Attending Tertiary Care Hospital of Bhuj, Kutch: A Cross-Sectional Study
}

\author{
Dhruven Ponkiya ${ }^{\circledR 1}$, Gyaneshwar Rao ${ }^{\circledR 2}$ \\ ${ }^{1}$ Post Graduate Student, Department of Surgery, Gujarat Adani Institute of Medical Science, Bhuj, Gujarat, India, ${ }^{2}$ Professor and Head, Department of Surgery, Gujarat \\ Adani Institute of Medical Science, Bhuj, Gujarat, IndiaO.
}

\section{Abstract}

Background: Haemorrhoids are abnormal engorgement of arteriovenous plexus in anal cushions lining the anal canal. As per the theory of sliding anal canal lining, weakening of supporting tissues of anal cushions lead to blood vessel descent. Present study was carried out to study the surgical profile of patients with hemorrhoidectomy so that we can throw a light on the etiopathogenesis of the patients with hemorrhoidectomy. Subjects and Methods: Present cross-sectional study was carried out at a tertiary care hospital of Bhuj in the department of general surgery among 200 patients who presented with symptoms suggestive of hemorrhoids. Information on socio demographic variables, types and degrees of haemorrhoids, age at diagnosis, risk factors, clinical manifestations, associated co-morbidities, methods used for diagnosis, management practices, and outcome of management was noted down by the investigators. Dietary history was taken they were classified as having vegetarian diet or mixed diet based on the answers given by them. Results: The incidence of hemorrhoids was more in upper class compared to the lower class where only $46 \%$ were found to be affected. But statistically the difference might not be significant. Incidence of hemorrhoids was less i.e. $24 \%$ among those who took only vegetarian diet compared to $76 \%$ among those who took mixed diet. Bleeding was present in the majority i.e. $95 \%$ of the patients followed by constipation in $90 \%$ of the cases which was followed by pain in the anal region in $86 \%$ of the cases and prolapse was seen in $84 \%$ of the cases. Conclusion: Haemerrhoids are one of the common diseases observed in patients below 40 years of age, especially if they are under stress. Proper diet, which is inclusive of adequate quantities of fibre as well as with less spice, is essential to prevent this disease.

Keywords: Bleeding, Cross-sectional study, Diet, Haemerrhoids

Corresponding Author: Gyaneshwar Rao, Professor and Head, Department of Surgery, Gujarat Adani Institute of Medical Science, Bhuj, Gujarat, India0.

E-mail: drpiyushpujara@gmail.com

Received: 22 December 2019

Revised: 25 January 2020

Accepted: 31 January 2020

Published: 26 May 2020

\section{Introduction}

Haemorrhoids are abnormal engorgement of arteriovenous plexus in anal cushions lining the anal canal. As per the theory of sliding anal canal lining, weakening of supporting tissues of anal cushions lead to blood vessel descent.

Even though a common condition in clinical practice; its true prevalence is unknown due to the embarrassment involved in seeking treatment among the affected. Haemorrhoids is estimated to affect about a third of the population. ${ }^{[1]}$ More than half of men and women above 50 years of age are at risk of developing haemorrhoid symptoms during their lifetime. ${ }^{[2]}$ More than the men and women aged 50 years will experience hemorrhoid symptoms at least once during their lifetime. ${ }^{[3]}$ However, there have been incidences where children and the elderly have also been diagnosed with this condition. ${ }^{[4,5]}$ Hemorrhoid disease is said to be the fourth leading outpatient gastrointestinal diagnosis, accounting for 3.3 million ambulatory care visits in the United States. ${ }^{[6]}$ Although so common, only around 4\% seek medical help. ${ }^{[7]}$

Near anus and near rectum, there is swelling of the blood vessels which leads to the occurrence of the hemorrhoids. The veins which commonly get affected and which can lead to hemorrhoids are usually seen in the lower part of the anus and rectum. Due to swelling, the walls of these veins get stretched, it becomes thin, and due to regular passage of the hard stools, give rise to hemorrhoids. It has been commonly said that almost everyone may get affected due to hemorrhoids. ${ }^{[8]}$

The actual cause of hemorrhoids remains unknown. ${ }^{[9]}$ But it is proposed to be caused by temperament, body habits, cus- 
toms, passions, sedentary life, tight-laced clothes, climate. ${ }^{[10]}$ Patients with spinal cord injuries constipation, chronic diarrhea, poor bathroom habits, postponing bowel movements, and a poor-fiber diet are also considered to be contributing causes. ${ }^{[11]}$ Other causes that have been attributed to this condition are genetic predisposition, increased intra-abdominal pressure from many causes, including prolonged forceful valsalva defecation, obstruction of venous outflow secondary to pregnancy, and constipated stool in the rectal ampulla. ${ }^{[12,13]}$

Present study was carried out to study the surgical profile of patients with hemorrhoidectomy so that we can throw a light on the etiopathogenesis of the patients with hemorrhoidectomy.

\section{Subjects and Methods}

Present study was hospital based cross sectional study. It was carried out at a tertiary care hospital of Bhuj in the department of general surgery among 200 patients who presented with symptoms suggestive of hemorrhoids during the study period from January 2019 to September 2019. Institutional Ethics Committee permission was taken after presenting the proposal for the present study. After the clearance from the Institutional Ethics Committee consent form was created as per Institutional Ethics Committee norms. Written consent from each and every patient willing to participate in the present study was taken.

Inclusion criteria were patients with confirmed diagnosis of haemorrhoids; age 35-70 years. Exclusion criteria were haemorrhoids patients but having other serious co-morbidities; bed ridden patients; not willing to be part of this study. Study questionnaire was prepared for the present study and then it was tested and approved by all authors involved in the present study. Thus the data was collected in the pre designed, pre tested, and semi structured study questionnaire.

Information on socio demographic variables, types and degrees of haemorrhoids, age at diagnosis, risk factors, clinical manifestations, associated co-morbidities, methods used for diagnosis, management practices, and outcome of management was noted down by the investigators. Dietary history was taken they were classified as having vegetarian diet or mixed diet based on the answers given by them. Patients with symptoms were asked as to since what time they were having the symptoms. Then we classified them into those having symptoms since less than one year and having symptoms with more than one year of duration. The anorectoal examination was carried out for each and every patient included in the present study. The hemorrhoids were examined thoroughly and classified into different grades. Symptoms of the patients were also noted in the chronological orders and recorded in the study questionnaire. Presence of fissure or peri anal skin tag was confirmed for each and every patient included in the present study.
Statistical analysis

The recorded data was compiled and entered in a spreadsheet computer program (Microsoft Excel 2007) and then exported to data editor page of SPSS version 15 (SPSS Inc., Chicago, Illinois, USA). Descriptive statistics included computation of percentages, means and standard deviations. For all tests, confidence level and level of significance were set at $95 \%$ and $5 \%$ respectively.

\section{Results}

Majority of the patients $42 \%$ were in the age group of $31-40$ years followed by $31 \%$ in the age group of $41-50$ years. [Table 1]. The number affected by hemorrhoids was more in males i.e. $57.5 \%$ compared to $42.5 \%$ for females. Thus the incidence of hemorrhoids is more in males compared to females [Table 2].

The incidence of hemorrhoids was more in upper class compared to the lower class where only $46 \%$ were found to be affected. But statistically the difference might not be significant.

Incidence of hemorrhoids was less i.e. $24 \%$ among those who took only vegetarian diet compared to $76 \%$ among those who took mixed diet i.e. vegetarian as well as non-vegetarian diet. Thus non vegetarian diet can predispose a person to the risk of haemorrhoids [Table 3]. $60.5 \%$ of the patients had third grade of hemorrhoids compared to $39.5 \%$ of the patients with fourth grade hemorrhoids. No patient had first or second grade of hemorrhoids [Table 4]. Bleeding was present in the majority i.e. $95 \%$ of the patients followed by constipation in $90 \%$ of the cases which was followed by pain in the anal region in $86 \%$ of the cases and prolapse was seen in $84 \%$ of the cases. One patient had more than one symptoms complex [Table 5]. On anorectal examination, it was found that $42 \%$ of the patients had fissure and $24 \%$ of the patients had peri anal skin tag. Anorectal examination was within normal limits in $35 \%$ of the cases.

\begin{tabular}{|lll|}
\hline \multicolumn{3}{|c|}{ Table 1: Age wise distribution in study group. } \\
\hline $\begin{array}{l}\text { Age Group in } \\
\text { years }\end{array}$ & Number & Percentage (\%) \\
$31-40$ & 84 & 42 \\
$41-50$ & 62 & 31 \\
$51-60$ & 30 & 15 \\
$61-70$ & 24 & 12 \\
Total & 200 & 100 \\
\hline
\end{tabular}




\begin{tabular}{lll}
\hline Table 2: Gender wise distribution of Study Participants \\
\hline Gender & Number & Percentage (\%) \\
Male & 115 & 57.5 \\
Female & 85 & 42.5 \\
Total & 200 & 100 \\
\hline
\end{tabular}

Table 3: Distribution of study population as per dietary pattern

\begin{tabular}{lll}
\hline Diet & Number & Percentage (\%) \\
Vegetarian & 48 & 24 \\
Mixed & 152 & 76 \\
Total & 200 & 100 \\
\hline
\end{tabular}

Table 4: Distribution of study population as per grading of haemorrhoids

\begin{tabular}{lll}
\hline Grades & Number & Percentage (\%) \\
\hline Third grade & 121 & 60.5 \\
\hline Fourth grade & 79 & 39.5 \\
Total & 200 & 100 \\
\hline
\end{tabular}

Table 5: Distribution of study population as per grading of haemorrhoids

\begin{tabular}{lll}
\hline Grades & Number & Percentage (\%) \\
Bledding & 190 & 95 \\
Constipation & 180 & 90 \\
Pain & 170 & 85 \\
Prolapse & 172 & 86 \\
\hline
\end{tabular}

\section{Discussion}

Hemorrhoids or piles are one of the most common disorders seen among the young adults. It is estimated that more than $50 \%$ of the males and females would suffer from piles before they are of 50 years of age. The age range of this study was 35-68 years. In this study the most common age group was $35-45$ with $41 \%$ cases distributed in this group. Next most common age group was $46-55$ age groups. Mean age was $47 \pm 3.2$ years. This was similar to the findings of previous studies where majority of cases were between 45 and 49 years or $\geq 40$ years. ${ }^{[14,15]}$ However, majority of cases were reported between 20-39 years in a study done in Mysore, India, ${ }^{[16]}$ between 20-49 years in a study done in Taiwan 17 and between 51-70 years in a study done in Bhubaneswar, India. ${ }^{[17]}$

In this study out of total 41 cases, $51 \%$ in open method belonged to 35-45 age group while in stapler group $41 \%$ belonged to age group of 35-45. Sachin et al concluded similar results with 26\% were in the age group 21-30 years in the open hemorrhoidectomy group, $28 \%$ were in the age group 21-30 years, and $26 \%$ were in the age group $31-40$ years in stapler method. ${ }^{[18]}$

Out of total cases, male formed $56 \%$ and rest $44 \%$ formed by females, there is no any significant association of gender distribution in two surgical groups, also there is no any significance between age groups and gender distribution in study groups. The proportion of males outnumbered the proportion of females in this study as also reported in several other studies. ${ }^{[15,16,19]}$ The reason for this could be that women hesitate more than men to discuss anorectal problems and also tend to avoid anal examination for the diagnosis of haemorrhoids. Gravie et al also concluded no significant differences between the 2 groups with respect to gender. ${ }^{[20]}$ Sachin et al also supported our higher male findings. ${ }^{[18]}$ All these findings were similar with our study findings. Out of total male $46 \%$ male were in open group and $54 \%$ were in stapler group. While out of total females $54 \%$ female where in open group and $46 \%$ were in stapler group. This association was not found to be significant. This was in accordance with Thejeswi et al study in which out of 20 stapled group cases, $14(70 \%)$ were males and $6(30 \%)$ were females.

With 79\% study subjects having mixed diet which is found to be associated significantly. This was in accordance to a study by Khan et al, who reported that out of 311 patients in his study, only 66 were on vegetarian diet. ${ }^{[20]}$ Inadequate fibre intake was found to be one of the risk factors of hemorrhoids as was high intake of spicy food. ${ }^{[21,22]}$ Increasing the dietary fiber was reported to improve the incidence of hemorrhoids. This is probably as fibre reduced constipation, which is one of the risk factors of hemorrhoids. ${ }^{[23]}$

Hemorrhoid grade is not found to be significant in study population, with grade III forming $54 \%$ and grade IV forming $46 \%$ of total cases as also reported in a Pakistani study where $84.2 \%$ cases were of third degree variety. ${ }^{[24]}$ In a study by Khan et al majority $53.3 \%$ of patients had third degree haemorrhoids. ${ }^{[16]}$ In this study bleeding $98 \%$ was found to be most common symptom, next was constipation $89 \%$ in study population. These are not found to be significantly distributed in either of the two groups. As these haemorrhoids prolapse through the analcanal, the tissue can become traumatised and friable, leading to bleeding. ${ }^{[25]}$

In study done in USA, constipation was associated with an increased prevalence of haemorrhoids. ${ }^{[26]}$ A multivariate analysis identified constipation and straining during delivery for more than 20 minutes as significant predictors of haemorrhoids. ${ }^{[27]}$ This is explained by the fact that constipation increases the intra-abdominal pressure. This might induce obstruction in venous return and later engorgement of haemorrhoidal plexus. Passage of hard stools increases shearing force on anal cushions which also predisposes to haemorrhoids. Out of total 100 cases 67 showed additional findings, fissure in 44 cases and 23 showed perianal skin tag. There was no signifi- 
cance in distribution of these cases in surgical groups. Maurya et al study out of total anorectal findings $65 \%$ had a fissure and $35 \%$ had fistula, they also did not find any significance in two study groups. ${ }^{[28]}$ While Chauhan et al study showed only $5 \%$ cases with anal fissures. ${ }^{29]}$

The limitation in this study was the less number of study subjects. Larger sample size is required to assess the etiology of hemorrhoids.

\section{Conclusion}

Haemerrhoids are one of the common diseases observed in patients below 40 years of age, especially if they are under stress. Proper diet, which is inclusive of adequate quantities of fibre as well as with less spice, is essential to prevent this disease. Thus, proper education must be done to such patients to change their lifestyle so that they can take proper precautions and avoid unnecessary complication.

\section{References}

1. Loder PB, Kamm MA, Nicholls RJ, Phillips RKS. Haemorrhoids: Pathology, pathophysiology and aetiology. Br J Surg. 1994;81(7):946-954. Available from: https://dx.doi.org/10. 1002/bjs.1800810707. doi:10.1002/bjs. 1800810707.

2. Bailey HR. Innovations for age-old problem: hemorrhoids in the female patient. Female Patient. 2004;29:17-23.

3. Kumar S. Prevalence of Post-Operative Wound Infection. Asian J Med Res. 2018;7(2):5-08.

4. Heaton ND, Davenport M, Howard ER. Symptomatic hemorrhoids and anorectal varices in children with portal hypertension. J Pediatr Surg. 1992;27(7):833-835. Available from: https://dx.doi.org/10.1016/0022-3468(92)90377-j. doi:10.1016/0022-3468(92)90377-j.

5. Pietroletti R, Navarra L, Maggi G, Leardi S, Simi M. Diagnosis and treatment of haemorrhoids in the elderly: results from 291 patients. Tech Coloproctol. 2000;3(3):127-130. Available from: https://dx.doi.org/10.1007/s101510050031. doi:10.1007/s101510050031.

6. Everhart JE, Ruhl CE. Burden of Digestive Diseases in the United States Part I: Overall and Upper Gastrointestinal Diseases. Gastroenterol. 2009;136(2):376386. Available from: https://dx.doi.org/10.1053/j.gastro.2008. 12.015. doi:10.1053/j.gastro.2008.12.015.

7. Liebach JR, Cerda JJ. Hemorrhoids: modern treatment methods. Hosp Med. 1991;53:68-68.

8. Lohsiriwat V. Hemorrhoids: From basic pathophysiology to clinical management. World J Gastroenterol. 2012;18(17):2009-2009. Available from: https://dx.doi.org/10. 3748/wjg.v18.i17.2009. doi:10.3748/wjg.v18.i17.2009.

9. Madoff RD, Fleshman JW. American gastroenterological association technical review on the diagnosis and treatment of hemorrhoids 1 1This literature review and the recommendations therein were prepared for the American Gastroenterological Association Clinical Practice Committee. The paper was approved by the Committee on January 8,2004 , and by the
AGA Governing Board on February 13, 2004. Gastroenterol. 2004;126(5):1463-1473. Available from: https://dx.doi.org/10. 1053/j.gastro.2004.03.008. doi:10.1053/j.gastro.2004.03.008.

10. Dennison AR, Whiston RJ, Rooney S, Morris DL. The management of hemorrhoids. Am J Gastroenterol. 1989;84:475-81.

11. Andrews CN, Storr M. The pathophysiology of chronic constipation. Can J Gastroenterol. 2011;25:16-21.

12. Pfenninger JL, Surrell J. Nonsur gical treatment options for internal hemorrhoids. Am Fam Phys. 1995;52:821-855.

13. Parks AG. Surgical treatment of haemorrhoids. Br J Surg. 1956;43:337-345.

14. Ali SA, Shoeb MFR. Study of risk factors and clinical features of hemorrhoids. Int Surg J. 2017;4(6):19361936. Available from: https://dx.doi.org/10.18203/2349-2902. isj20172051. doi:10.18203/2349-2902.isj20172051.

15. Khan RM, Malik I, Ansari AH, Zulkifle M, E. A STUDY ON ASSOCIATED RISK FACTORS OF HAEMORRHOIDS. J Bio Sci Opinion. 2015;3(1):36-38. Available from: https://dx.doi.org/10.7897/2321-6328.0318. doi:10.7897/2321-6328.0318.

16. Naveen S, Lenka BN, Nayak AK. A clinical study of secondary haemorrhoids and its management. J Pharm Biomed Sci. 2016;6:238-278.

17. $\mathrm{Hu}$ WS, Lin CL. Hemorrhoid is associated with increased risk of peripheral artery occlusive disease: A nationwide cohort study. J Epidemiol. 2017;27:574-77.

18. Sachin ID, Muruganathan OP. Stapled hemorrhoidopexy versus open hemorrhoidectomy: a comparative study of short term results. Int Surg J. 2017;4(2):472-472. Available from: https://dx.doi.org/10.18203/2349-2902.isj20164791. doi:10.18203/2349-2902.isj20164791.

19. Riss S, Weiser FA, Schwameis K, Riss T, Mittlböck M, Steiner $\mathrm{G}$, et al. The prevalence of hemorrhoids in adults. Int $\mathrm{J}$ Colorectal Dis. 2012;27(2):215-220. Available from: https:// dx.doi.org/10.1007/s00384-011-1316-3. doi:10.1007/s00384011-1316-3.

20. Khan RM, Malik I, Ansari AH, Zulkifle M, E. A STUDY ON ASSOCIATED RISK FACTORS OF HAEMORRHOIDS. J Bio Sci Opinion. 2015;3(1):36-38. Available from: https://dx.doi.org/10.7897/2321-6328.0318. doi:10.7897/2321-6328.0318.

21. Johanson JF, Sonnenberg A. The prevalence of hemorrhoids and chronic constipation. Gastroenterol. 1990;98(2):380-386. Available from: https://dx.doi.org/10.1016/0016-5085(90) 90828-o. doi:10.1016/0016-5085(90)90828-o.

22. Loder PB, Kamm MA, Nicholls RJ, Phillips RK. Hemorrhoids: Pathology, pathophysiology and etiology. Br J Surg. 1994;81:946-54.

23. Demir H, Karaman K, Ercan M, Kocer HB, Celebi F. Comparison of two procedures for symptomatic hemorrhoidal disease: Ligation under Vision and Ferguson Hemorrhoidectomy A retrospective cohort study. Pak J Med Sci. 2017;33(1):90-95. Available from: https://dx.doi.org/10.12669/pjms.331.11266. doi:10.12669/pjms.331.11266.

24. Chawla T, Turab P, Athar A. Stapled Hemorrhoidopexy: The Aga Khan University Hospital Experience. Saudi J Gastroenterol. 2009;15(3):163-163. Available from: https://dx.doi.org/ 10.4103/1319-3767.45358. doi:10.4103/1319-3767.45358. 
25. Ganz RA. The Evaluation and Treatment of Hemorrhoids: A Guide for the Gastroenterologist. Clinical Gastroenterology and Hepatology. 2013;11(6):593-603. Available from: https://dx.doi.org/10.1016/j.cgh.2012.12.020. doi:10.1016/j.cgh.2012.12.020.

26. Peery AF, Sandler RS, Galanko JA, Bresalier RS, Figueiredo JC, Ahnen DJ, et al. Risk Factors for Hemorrhoids on Screening Colonoscopy. PLOS ONE. 2015;10(9):e0139100e0139100. Available from: https://dx.doi.org/10.1371/journal. pone.0139100. doi:10.1371/journal.pone.0139100.

27. Poskus T, e DB, Drasutiene G, Samalavicius NE, Barkus A, Barisauskiene A, et al. Haemorrhoids and anal fissures during pregnancy and after childbirth: a prospective cohort study. BJOG Int J Obs Gynaecol. 2014;121(13):1666-1671. Available from: https://dx.doi.org/10.1111/1471-0528.12838. doi:10.1111/1471-0528.12838.

28. Maurya V, Jain V, Jolly S. Comparative study of stapler hemorrhoidectomy and open hemorrhoidectomy. J Med Sci Clin Res. 2017;5(4):19892-19904.
29. Chauhan H, Vaishnav UG. A comparative study of Longo's procedure without stapler versus open hemorrhoidectomy in 2nd and 3rd degree hemorrhoids. IAIM. 2016;3(2):25-30.

Copyright: (C) the author(s), 2020. It is an open-access article distributed under the terms of the Creative Commons Attribution License (CC BY 4.0), which permits authors to retain ownership of the copyright for their content, and allow anyone to download, reuse, reprint, modify, distribute and/or copy the content as long as the original authors and source are cited.

How to cite this article: Ponkiya D, Rao G. Prevalence and the Risk Factors of Haemorrhoids among the Patients Attending Tertiary Care Hospital of Bhuj, Kutch: A Cross-Sectional Study. Acad. J Surg. 2020;3(1):37-41.

DOI: dx.doi.org/10.47008/ajs/2020.3.1.8

Source of Support: Nil, Conflict of Interest: None declared. 